\title{
Impact of preventing exacerbations on deterioration of health status in COPD
}

\author{
S. Spencer*, P.M.A. Calverley", P.S. Burge ${ }^{\Uparrow}$, P.W. Jones ${ }^{+}$
}

Impact of preventing exacerbations on deterioration of health status in COPD. S. Spencer, P. M.A. Calverley, P.S. Burge, P.W. Jones. (C) ERS Journals Ltd 2004. ABSTRACT: Exacerbations of chronic obstuctive pulmonary disease (COPD) are associated with worse health status. The Inhaled Steroids in Obstructive Lung Disease in Europe (ISOLDE) study showed that treatment with fluticasone propionate (FP) reduced exacerbation frequency and the rate of deterioration in health status as compared with placebo. The present study analysed these data to test whether the effect of FP on health status was attributable to its effect on exacerbations.

Rates of deterioration in St George's Respiratory Questionnaire (SGRQ) total score were obtained for 613 patients with moderate to severe COPD followed for a maximum of 3 yrs. Exacerbation rates were skewed and could not be normalised, therefore, patients were stratified into three exacerbation groups: none, infrequent $(<1.65$ exacerbations $\left.\cdot \mathrm{yr}^{-1}\right)$ and frequent $\left(>1.65\right.$ exacerbations $\left.\cdot \mathbf{y r}^{-1}\right)$.

There were 91 patients with no exacerbations, 285 with infrequent exacerbations and 235 with frequent exacerbations. Frequent exacerbations were independently associated with a worse baseline SGRQ score $(\mathbf{p}<\mathbf{0 . 0 0 0 1})$ and a more rapid rate of deterioration in health status $(p=0.0003)$. Exacerbation frequency and rate of decline in forced expiratory volume in one second were independently related to the rate of deterioration in SGRQ score.

Statistical modelling showed the beneficial effect of fluticasone propionate on deterioration in health status to be largely due to its effect on exacerbation frequency. Eur Respir J 2004; 23: 698-702.
*Dept of Health and Social Care, Brunel University, Isleworth, ${ }^{\#}$ University Hospital Aintree, Aintree NHS Trust, Liverpool,

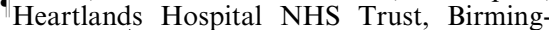
ham, and 'Respiratory Medicine, St George's Hospital Medical School, London, UK.

Correspondence: S. Spencer, Dept of Health and Social Care, Brunel University, Borough Road, Isleworth TW7 5DU, UK.

Fax: 442088918211

E-mail: Sally.Spencer@brunel.ac.uk

Keywords: Chronic obstructive pulmonary disease

exacerbation

health status

quality of life

Received: October 292003

Accepted after revision: February 172004

The current analysis was supported by a grant from GlaxoSmithKline, UK.
Chronic obstructive pulmonary disease (COPD) is a complex disease characterised by incompletely reversible airways obstruction, progressive loss of lung function, recurrent exacerbations and poor health. The relationship between health status and exacerbations is well established; poor health is associated with a higher frequency of exacerbations $[1,2]$, an increased likelihood of hospitalisation [3] and increased mortality [4]. Recent meta-analyses have reported that inhaled corticosteroids (ICS) have a minimal or no effect on the rate of decline in forced expiratory volume in one second (FEV1) [5, 6], but they do reduce the severity [7] and frequency of exacerbations [8], and reduce the rate of deterioration in health status [8, 9]. A number of recent studies have also shown that inhaled therapy can reduce exacerbations and improve health status over 1 yr [10-12]. While there appears to be an association between exacerbations and health status, the mechanism has not yet been established. Furthermore, there is no direct evidence that reducing exacerbation frequency can improve health. The aim of the present study was to re-analyse data from the 3-yr Inhaled Steroids in Obstructive Pulmonary Lung Disease in Europe (ISOLDE) study of fluticasone propionate (FP) in COPD [8], using statistical models, to test whether there is evidence of a direct association between exacerbation frequency and deterioration in health status, and whether the effect of FP on health status is attributable to its effects on exacerbation frequency.

\section{Methods}

Full details of the study methodology, patient selection, efficacy assessments and statistical analyses have been published previously [8].

In brief, the study enrolled current or former smokers aged 40-75 yrs with nonasthmatic COPD. The study used a randomised, double-blind, placebo-controlled, parallel-group design and was conducted in 18 hospitals in the UK.

The St George's Respiratory Questionnaire (SGRQ) is a supervised, self-administered measure designed specifically for use in airways disease. It is a 50-item survey scored from $0-100$, where 0 indicates best health, 100 indicates worst health and a difference or change in score of 4 units is clinically significant [13]. The SGRQ has been shown to be a valid measure of health impairment in chronic airflow limitation [14], to respond to changes in therapy [15] and to be a predictor of mortality in COPD $[4,16]$. The total score is used as the outcome in the current analysis.

Use of ICS was discontinued and all patients entered an 8 -week run-in period. Patients were then randomised to receive FP $500 \mu \mathrm{g}$ twice daily via metered-dose inhaler and spacer device or a placebo. Patients were permitted to use salbutamol and ipratropium bromide as required. Other permitted treatments were equally distributed between the treatment groups. 
The SGRQ was completed after the run-in period and then 6-monthly for $3 \mathrm{yrs}$, whether they had experienced a recent exacerbation or not. Exacerbations, defined as "chest problems requiring treatment with antibiotics and/or oral corticosteroids", were recorded at 3-month intervals by patient self-report. No specific instructions were given to physicians concerning treatment decisions. Patients were withdrawn from the study if continuance was considered detrimental, or if they required more than two short courses of oral corticosteroids in any 3-month period or maintenance oral corticosteroid or ICS treatment. Rates of deterioration in SGRQ total score were obtained for 613 patients with moderate to severe COPD followed for a maximum of $3 \mathrm{yrs}$.

Exacerbation rate was calculated as the number of exacerbations per year. If a patient withdrew during the study, the exacerbation rate was calculated by dividing the number of exacerbations experienced during the treatment period by the time spent on treatment. Normalising transformations of the exacerbation rate did not adequately combat the problem of a skewed distribution, therefore, the current study categorised the patients in the following way: nonexacerbators (no exacerbations in the entire 3-yr period), infrequent exacerbators and frequent exacerbators. The latter two categories were determined using a median split (1.65 exacerbations $\cdot \mathrm{yr}^{-1}$ ) of the annualised exacerbation rate for patients who had exacerbations. It should be noted that this median value is higher than that reported by BURGE et al. [8], as the latter calculated the average exacerbation rate for all randomised patients whereas the current study included only the 613 patients for whom a rate of deterioration in SGRQ total score was obtainable. The annual exacerbation rate was not significantly different between the two treatment arms in this group of patients (Mann-Whitney U-test, $\mathrm{p}=0.05$ ), therefore, the analyses did not control for treatment unless otherwise specified.

Baseline differences between the proportion of males and females having exacerbations, and between the proportion of smokers and exsmokers having an exacerbation were examined using Fisher's exact test. Baseline differences in age, SGRQ total score and FEV1\% predicted between exacerbators and nonexacerbators were tested using unpaired t-tests. The relationship between exacerbation category and health status scores was measured using analysis of variance, controlling for differences between study centres. Rates of decline in health status and FEV1 were calculated using unpaired multi-level hierarchical model [8]. To examine the relationship between change in health status over time and exacerbation frequency, rate of change in health status from 6 months onwards was used as the dependent variable in multivariate analyses. For some analyses, baseline FEV1\% pred was subdivided into two categories, according to American
Thoracic Society severity criteria (ATS) [17]: mild (postbronchodilator FEV1 $\geqslant 50 \%$ pred) and moderate to severe (postbronchodilator FEV1 $<50 \%$ pred). Exacerbation category, decline in FEV1 and treatment group were the independent variables with all analyses controlling for study centre. The authors hypothesis, a priori, was that there would be an interaction between the effect of treatment and exacerbation frequency on SGRQ change. When testing this hypothesis, statistical significance was accepted at $\mathrm{p}<0.05$.

\section{Results}

\section{Baseline characteristics and exacerbation frequency}

Rates of deterioration in SGRQ total score were obtained for 613 patients and these patients were included in the analyses. The proportion of smokers and exsmokers at baseline did not differ between exacerbators and nonexacerbators, although age differed between the groups. Males were less likely to have an exacerbation than females (table 1). Baseline FEV1 \% pred was significantly lower in patients who subsequently had exacerbations, as compared to those who did not. The baseline SGRQ score was also significantly worse, both statistically and clinically, in patients who subsequently experienced an exacerbation during the study, as compared to those who remained exacerbation-free $(\mathrm{p}<0.0001)$. To determine whether the relationship between SGRQ score and exacerbation frequency was influenced by baseline disease severity, this comparison was repeated with FEV1 category (ATS criteria) included as an independent variable. Baseline SGRQ score was significantly higher in patients with more severe obstruction, however, there was no significant interaction between disease severity and exacerbation frequency on the effect on SGRQ score ( $\mathrm{p}=0.4)$.

In patients who had at least one exacerbation during the study, the baseline FEV1 was significantly lower in those with frequent exacerbations $(\mathrm{p}<0.0001)$ (table 1). Baseline SGRQ score was also significantly worse (fig. 1). The 4-unit difference in score between frequent and infrequent exacerbators was both clinically and statistically significant $(\mathrm{p}=0.03)$. There was no difference in sex, age or smoking history between frequent and infrequent exacerbators ( $p>0.05$ in each case).

\section{Exacerbation frequency and change in health status}

Patients who remained free of exacerbations deteriorated at a rate of 2 SGRQ units $\cdot \mathrm{yr}^{-1}(95 \%$ confidence interval (CI) 1.7-2.3) whereas exacerbators deteriorated more rapidly at a rate of $2.6 \mathrm{SGRQ}$ units $\cdot \mathrm{yr}^{-1}(95 \%$ CI 2.4-2.8) $(\mathrm{p}=0.004)$. This

Table 1.-Baseline characteristics by exacerbation status: exacerbators versus nonexacerbators

\begin{tabular}{|c|c|c|c|c|c|c|}
\hline & \multicolumn{3}{|c|}{ Number of exacerbations } & \multicolumn{3}{|c|}{ Frequency of exacerbations } \\
\hline & None & $\geqslant 1$ & $\mathrm{p}$-value & $<1.65 \cdot \mathrm{yr}^{-1}$ & $>1.65 \cdot \mathrm{yr}^{-1}$ & $\mathrm{p}$-value \\
\hline Subjects n & 93 & 520 & & 291 & 286 & \\
\hline Sex M \% & 86 & 73 & 0.009 & 72 & 74 & 0.7 \\
\hline Age yrs & $65 \pm 7$ & $64 \pm 7$ & 0.06 & $63 \pm 7$ & $64 \pm 7$ & 0.05 \\
\hline Current smokers $\%$ & 52 & 48 & 0.6 & 48 & 48 & 0.9 \\
\hline SGRQ total score & $42 \pm 17$ & $50 \pm 17$ & $<0.0001$ & $48 \pm 18$ & $52 \pm 15$ & 0.03 \\
\hline FEV1 \% pred & $55 \pm 15$ & $49 \pm 15$ & 0.001 & $53 \pm 15$ & $45 \pm 13$ & $<0.0001$ \\
\hline
\end{tabular}

Data are presented as mean \pm SD unless otherwise stated. Mean exacerbation rate in patients with exacerbations $>0$ and $<1.65 \cdot \mathrm{yr}^{-1} \mathrm{was} 0.9 \cdot \mathrm{yr}^{-1}$, and in patients with exacerbations $>1.65 \cdot \mathrm{yr}^{-1}$ was $2.8 \cdot \mathrm{yr}^{-1}$. M: male; SGRQ: St Georges Respiratory Questionnaire; FEV1: forced expiratory volume in one second. 


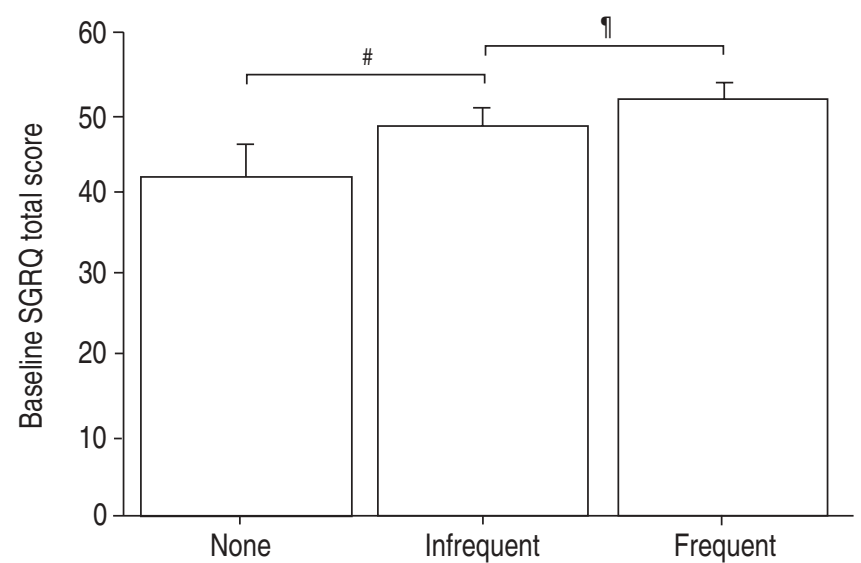

Fig. 1.- Baseline St Georges Respiratory Questionnaire (SGRQ) scores by exacerbation category. Data are presented as mean and $95 \%$ confidence intervals (bars). Baseline SGRQ score was missing for six infrequent exacerbators and for five frequent exacerbators. High score indicates worse health. ${ }^{\#}: \mathrm{p}=0.002 ;$ : $\mathrm{p}=0.03$. None, $\mathrm{n}=91$; infrequent, $n=279$; frequent, $n=230$.

difference was not influenced by baseline severity as indexed by ATS category (exacerbation category*ATS category, $\mathrm{p}=0.8$ ). In the patients who experienced one or more exacerbations, frequent exacerbators deteriorated significantly faster (2.9 SGRQ units $\left.\cdot \mathrm{yr}^{-1}\right)$ than infrequent exacerbators (2.4 SGRQ units $\cdot \mathrm{yr}^{-1}$ ) (fig. 2). Further analysis showed that baseline score and annual rate of deterioration in SGRQ score were independently related to exacerbation status (i.e. exacerbators versus nonexacerbators; Chi-Squared $\mathrm{p}=0.0002$ and $\mathrm{p}=0.009$, respectively). This analysis was refined to compare frequent and infrequent exacerbators. Again, both the baseline SGRQ score and the rate of deterioration were independently related to the frequency of exacerbations (i.e. frequent versus infrequent exacerbators; Chi-Squared $\mathrm{p}=0.036$ and $\mathrm{p}=0.009$, respectively).

\section{FEV1 decline, exacerbations and change in health status}

In the 613 patients who could be evaluated for this analysis, the FEV1 declined at a rate of $54 \mathrm{~mL} \cdot \mathrm{yr}^{-1}(95 \% \mathrm{CI} 50-57)$ and

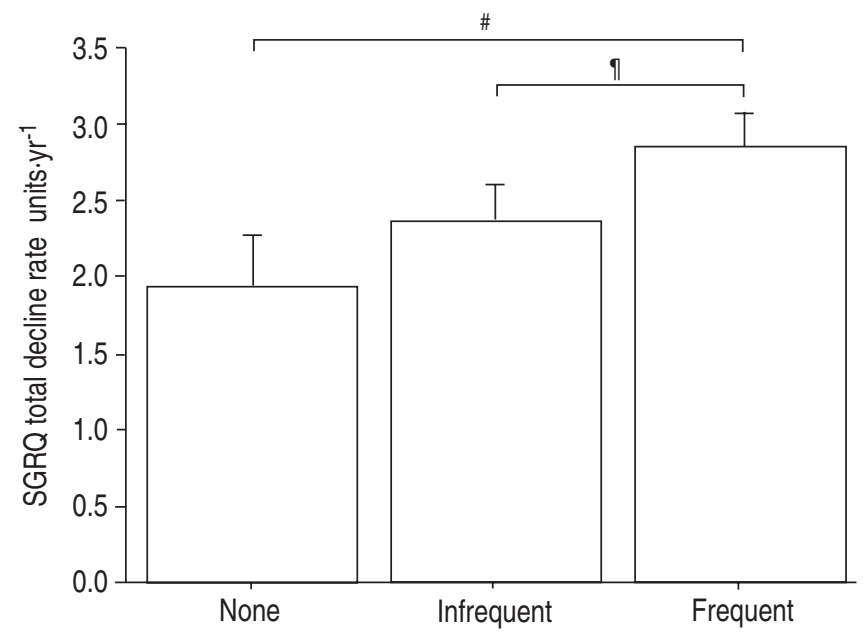

Fig. 2.-Deterioration in St Georges Respiratory Questionnaire (SGRQ) total score by exacerbation category. Data are presented as mean and $95 \%$ confidence intervals (bars). Higher score indicates faster deterioration in health. ${ }^{\#}: \mathrm{p}<0.0001 ;{ }^{\uparrow}: \mathrm{p}=0.004$. None, $\mathrm{n}=91$; infrequent, $n=285$; frequent, $n=235$. the SGRQ score deteriorated at a rate of 2.5 units $\cdot \mathrm{yr}^{-1}(95 \%$ CI 2.3-2.7). The changes in FEV1 and SGRQ scores were related $(\mathrm{r}=-0.20, \mathrm{p}<0.0001)$. In patients who remained exacerbation-free, the FEV1 declined at a rate of $50 \mathrm{~mL} \cdot \mathrm{yr}^{-1}$ (95\% CI 42-58) and at $55 \mathrm{~mL} \cdot \mathrm{yr}^{-1}(95 \%$ CI 51-59) in patients who had at least one exacerbation. Infrequent exacerbators declined by $55 \mathrm{~mL} \cdot \mathrm{yr}^{-1}(95 \% \mathrm{CI} 49-61)$ and frequent exacerbators by $54 \mathrm{~mL} \cdot \mathrm{yr}^{-1}(95 \%$ CI 50-58). Differences in FEV1 decline between exacerbators and nonexacerbators, and between frequent and infrequent exacerbators were not statistically significant (ANOVA, $\mathrm{p}=0.5$ ).

To clarify the relationship between deterioration in health status, decline in FEV1 and exacerbation frequency, the authors of the present study performed a multivariate analysis with change in SGRQ score as the dependent variable. In this model, exacerbation frequency was significantly related to a decline in SGRQ score ( $\mathrm{p}=0.0003)$ after accounting for FEV1. The decline rate of FEV1 also remained significantly related to the decline in SGRQ scores, after accounting for exacerbation frequency $(\mathrm{p}<0.0001)$. This analysis showed that both exacerbation frequency and rate of deterioration in FEV1 were independently related to the rate of decline in SGRQ total score.

\section{Effect of treatment on change in health status}

The primary analysis of the ISOLDE study showed a 38\% lower rate of deterioration in SGRQ score in patients receiving ICS (FP 2.0 units $\cdot \mathrm{yr}^{-1}$, placebo 3.2 units $\cdot \mathrm{yr}^{-1}$; $\mathrm{p}=0.004)$ [7]. To investigate the possible mechanisms for this, a multivariate analysis was first performed with change in SGRQ as the dependent variable, and exacerbation frequency and treatment group as independent variables. In this model, the dominant effect on SGRQ change was exacerbation category, although there was still a small significant difference in SGRQ slope of $15 \%$ between treatments (table 2). To test whether FP altered the relationship between SGRQ slope and exacerbation category, an interaction term was added for "treatment-by-exacerbation" (table 3). With this term in place, only exacerbation status remained a significant determinant of SGRQ change, i.e. the relationship between SGRQ and exacerbation category was the same in both treatment groups. In this model, the effect of FP on SGRQ slope was very small and not statistically significant.

The present study sought to test whether the relationship between change in health status and FEV1 decline was influenced by treatment. In a model that included FEV1 slope, treatment and an interaction term for "FEV1-by-treatment", a decline in FEV1 was found and it was the dominant covariate, although the effect of treatment remained significant (table 4). Finally, the current study combined all the covariates (FEV1 slope, exacerbation category and treatment group) in a single

Table 2. - Effect of treatment and exacerbation frequency on change in St Georges Respiratory Questionnaire (SGRQ) score

SGRQ score units $\cdot \mathrm{yr}^{-1} \quad \mathrm{p}$-value

Exacerbation frequency

$\begin{array}{ll}\text { None } & 2.0 \\ \text { Infrequent } & 2.4 \\ \text { Frequent } & 2.9 \\ \text { Treatment } & \\ \text { FP } & 2.2 \\ \text { Placebo } & 2.6\end{array}$

0.0003

2.4

2.9

2.2

0.02

Data are presented as mean or as p-value. FP: fluticasone proprionate. 
Table 3. - Relationship between deterioration in St Georges Respiratory Questionnaire (SGRQ) score, exacerbation group and treatment

SGRQ score units $\cdot \mathrm{yr}^{-1} \mathrm{p}$-value

\begin{tabular}{lll}
\hline Exacerbation group & & \\
$\quad$ None & 2.0 & 0.0003 \\
$\quad$ Infrequent & 2.4 & \\
$\quad$ Frequent & 2.9 & \\
Treatment & 2.3 & 0.1 \\
$\quad$ FP & 2.5 & 0.2 \\
$\quad$ Placebo & & 0.2 \\
\hline
\end{tabular}

Data are presented as mean or p-value. FP: fluticasone proprionate.

Table 4.-Relationship between deterioration in St Georges Respiratory Questionnaire (SGRQ) score, forced expiratory volume in one second $\left(F E V_{1}\right)$ decline and treatment

\begin{tabular}{lccc}
\hline & $\begin{array}{c}\text { FEV1 decline } \\
\mathrm{mL} \cdot \mathrm{yr}^{-1} \cdot 1 \text { unit } \\
\mathrm{SGRQ}^{-1}\end{array}$ & $\begin{array}{c}\text { SGRQ score } \\
\text { mean units } \cdot \mathrm{yr}^{-1}\end{array}$ & p-value \\
\hline $\begin{array}{l}\text { FEV1 decline rate } \\
\text { Treatment }\end{array}$ & -6.3 & & $<0.0001$ \\
$\quad$ FP & & 2.3 & 0.02 \\
$\quad$ Placebo & & 2.7 & 0.2 \\
FEV1 decline & & & \\
$*$ treatment & & & \\
\hline
\end{tabular}

FP: fluticasone proprionate.

model. Exacerbation category and FEV1 slope both remained the principal determinants of SGRQ change (both $p \leqslant 0.0002)$. There was still a small treatment effect of FP on SGRQ deterioration, but this was removed by the addition of a treatment-by-exacerbation term (as used in the model shown in table 3 ).

To summarise these models, exacerbation frequency and FEV1 decline were both significant determinants of the deterioration in SGRQ score. There was a small effect of FP on SGRQ slope that was independent of its effect on exacerbations (table 2), but much of the previously observed effect of FP on health status appears to be attributable to its effect on exacerbation rate, since the relationship between exacerbation rate and SGRQ was the same in both treatment groups (table 3). The model in table 4 shows that FP had effects on SGRQ slope that were independent of FEV1 decline (and any effect that FP may have had through an effect on FEV1 decline).

\section{Discussion}

The current study has shown that decline in FEV1 and the frequency of exacerbations are two separate factors that lead to deterioration in health status. Clearly, they are not the only factors, since patients who had no exacerbations over 3 yrs still showed deterioration in health status, even after the effect of FEV1 decline had been taken into account. The beneficial effect of high-dose ICS on deterioration in health appears to be largely attributable to its effect on the frequency of exacerbations. The lack of efficacy of FP on FEV1 decline precludes any formal test of the hypothesis that treatments that alter FEV1 slope will also improve the SGRQ slope. A previous observational study by SEEMUNGAL et al. [1] demonstrated an association between health status and the frequency of exacerbations over the preceding year, but could not establish causality. The health effects of an infective exacerbation of COPD are large and persist for $\geqslant 3$ months after the acute event [18]. This long recovery period might explain the association observed by SEEMUNGAL et al. [1]; patients who had frequent exacerbations were likely to have been in a recovery phase when assessed at the end of the study period, so they would have had worse SGRQ scores. Unlike SEEMUNGAL et al. [1], the authors of the present study were able to calculate rates of change in health over time from multiple measurements and have shown that the rate of deterioration in health over 3 yrs was linked to the average exacerbation rate over that time. This suggests that exacerbations have a cumulative effect on health.

The current study analysis cannot identify the mechanism for this association. It could be speculated that patients may not recover fully from an exacerbation. However, the current study did not include detailed information on exacerbation duration and, therefore, data to support this hypothesis is currently unavailable. A recent study has shown that the rate of recovery in SGRQ score appears to be normally distributed, i.e. there are patients who lie at the extremes of the recovery spectrum, although there is no clearly defined group of "slow recoverers" [18]. However, in patients who had one or more further episodes over the following 6 months, the degree of recovery following the index exacerbation was much less than in those who had no more acute events [18]. The findings in that study suggest that health status may fail to recover fully if exacerbations occur frequently and the current study has shown an increased rate of deterioration in health in patients with frequent exacerbations. Overall, the evidence suggests that a higher exacerbation frequency may have detrimental cumulative effects on health status. The current authors' findings complement recent reports that exacerbations have a small but significant cumulative effect on FEV1 $[19,20]$. It is not known whether this is a feature of all patients or just those in a subgroup whose airway function fails to recover fully following an exacerbation [21].

The ISOLDE study with fluticasone was the first long-term study to show a reduction in exacerbations in COPD [8]. More recently, similar reductions have been reported from a number of 1-yr studies using a variety of inhaled agents: longacting $\beta$-agonists (LABA), tiotropium or LABA combined with ICS [10-12, 22]. These studies also demonstrated health status gains using the SGRQ, which raises questions concerning the mechanisms responsible for this improvement. A reduction in exacerbations does not appear to account for all of the benefits reported, as differences in health status score between treatment groups are not always matched by differences in the effect on exacerbations [11, 12]. Furthermore, in some studies, health status gains developed within a few weeks of commencing treatment $[12,15]$. This suggests an effect on pulmonary function and a correlation has been shown between improvements in FEV1 and health status due to salmeterol therapy over a 16-week period [15]. Thus, it appears that beneficial effects of treatment on health may be mediated through different mechanisms, each with a different time course.

A post-hoc statistical modelling technique was used in the present study to test the hypothesis that reducing exacerbation frequency can reduce the health decline characteristic of COPD. The current analysis did not refute this hypothesis. A prospective experimental test of the hypothesis would require a study in which patients act as their own controls, and exacerbation frequency and health status are measured before and after the introduction of the treatment. The study would require a crossover design, a large number of patients, and pre- and post-treatment measurement periods of $\geqslant 1 \mathrm{yr}$ to ensure a sufficient number of exacerbations to test the hypothesis. The study would also have to be double-blind to 
avoid bias and, therefore, randomised with half of the patients receiving treatment for $1 \mathrm{yr}$, which would then be withdrawn for the next year. The technical and ethical issues involved would mean that it would be very difficult to design and successfully execute such a study. The modelling technique that has been used in this study may be the only practical way to address this question, although it can only fail to refute the hypothesis that changing exacerbation rate can change health status decline.

One problem affecting clinical trials is drop-out due to worsening COPD. In ISOLDE, criteria were set for withdrawing patients, based upon a high frequency of exacerbations. Another analysis of the ISOLDE study has shown that patients who dropped out or were withdrawn were deteriorating faster than those who remained in the study [23]. The findings of the present study are, therefore, not generalisable to this subgroup of rapidly progressive patients who have very frequent exacerbations. However, it may have made the analysis conservative, since patients who would have provided the greatest experimental "signal" were censored from the study (as is the case with nearly all long-term studies in COPD).

The current authors suggest that, taken together, there is sufficient evidence to suggest the possibility of a positivefeedback pathway involving exacerbations that can result in an accelerated worsening of chronic obstructive pulmonary disease: 1) exacerbations lead to a progressive fall in forced expiratory volume in one second $[19,20]$; 2) patients with a lower FEV1 have more frequent exacerbations [24]; 3a) exacerbations worsen health status [18]; 3b) frequent exacerbations are associated with an accelerated deterioration in health status (the present study); and 4) worse health status is associated with an increased likelihood of exacerbations (the present study). If this hypothesis is correct, therapies that have a worthwhile impact upon exacerbation frequency may modify chronic obstructive pulmonary disease progression in terms of lung function and overall health status, irrespective of any short-term symptomatic gains.

\section{References}

1. Seemungal TAR, Donaldson GC, Paul EA, Bestall JC, Jefferies DJ, Wedzicha JA. Effect of exacerbation on quality of life in patients with chronic obstructive pulmonary disease. Am J Respir Crit Care Med 1998; 157: 1418-1422.

2. Doll H, Grey-Amante P, Duprat-Lomon I, et al. Quality of life in acute exacerbation of chronic bronchitis: results from a German population study. Respir Med 2002; 96: 39-51.

3. Osman LM, Godden DJ, Friend JAR, Legge JS, Douglas JG. Quality of life and hospital re-admission in patients with chronic obstructive pulmonary disease. Thorax 1997; 52: 6771.

4. Domingo-Salvany A, Lamarca R, Ferrer M, et al. Healthrelated quality of life and mortality in male patients with chronic obstructive pulmonary disease. Am J Respir Crit Care Med 2002; 166: 680-685.

5. Sutherland ER, Allmers H, Ayas N, Venn AJ, Martin RJ. Inhaled corticosteroids reduce the progression of airflow limitation in chronic obstructive pulmonary disease: a metaanalysis. Thorax 2003; 58: 937-941.

6. Highland KB, Strange C, Heffner JE. Long-term effects of inhaled corticosteroids on FEV1 in patients with chronic obstructive pulmonary disease. Ann Intern Med 2003; 138: 969-973.

7. Paggiaro PL, Dahle R, Bakran I, Frith L, Hollingworth K,
Efthimiou J. Multicentre randomised placebo-controlled trial of inhaled fluticasone propionate in patients with chronic obstructive pulmonary disease. Lancet 1998; 351: 773 780 .

8. Burge PS, Calverley PMA, Jones PW, Spencer S, Anderson JA, Maslen TK. Randomised, double-blind, placebo controlled study of fluticasone propionate in patients with moderate to severe chronic obstructive pulmonary disease; the ISOLDE trial. BMJ 2000; 320: 1297-1303.

9. Spencer S, Calverley PMA, Burge PS, Jones PW. Health status deterioration in patients with COPD. Am J Respir Crit Care Med 2001; 163: 122-128.

10. Casaburi R, Mahler DA, Jones PW, et al. A long-term evaluation of once-daily inhaled tiotropium in chronic obstructive pulmonary disease. Eur Respir J 2002; 19: 217224.

11. Szfranski W, Cukier A, Ramirez A, et al. Efficacy and safety of budesonide/formoterol in the management of chronic obstructive pulmonary disease. Eur Respir J 2003; 21: 74-81.

12. Calverley PMA, Pauwels R, Vestbo J, et al. Combined salmeterol and fluticasone in the treatment of chronic obstructive pulmonary disease: a randomised controlled trial. Lancet 2003; 61: 449-456.

13. Jones PW. Interpreting thresholds for a clinically significant change in health status in asthma and COPD. Eur Respir $J$ 2002; 19: 398-404.

14. Jones PW, Quirk FH, Baveystock CM, Littlejohns P. A selfcomplete measure for chronic airflow limitation - the St George's Respiratory Questionnaire. Am Rev Respir Dis 1992; 145: 1321-1327.

15. Jones PW, Bosh TK. Changes in quality of life in COPD patients treated with salmeterol. Am J Respir Crit Care Med 1997; 155: 1283-1289.

16. Oga T, Nishimura K, Tsukino M, Sato S, Hajiro T. Analysis of the factors related to mortality in chronic obstructive pulmonary disease. Am J Respir Crit Care Med 2003; 167: 544-549.

17. American Thoracic Society. Standards for the diagnosis and care of patients with chronic obstructive pulmonary disease. Am J Respir Crit Care Med 1995; 152: 77-79.

18. Spencer S, Jones PW. Time course of recovery of health status following an infective exacerbation of chronic bronchitis. Thorax 2003; 58: 589-593.

19. Donaldson GC, Seemungal TAR, Bhowmik A, Wedzicha JA. Relationship between exacerbation frequency and lung function decline in chronic obstructive pulmonary disease. Thorax 2002; 57: 847-852.

20. Kanner RE, Anthonisen NR, Connett JE. Lower respiratory illnesses promote FEV1 decline in current smokers but not ex-smokers with mild chronic obstructive pulmonary disease: results from the lung health study. Am J Respir Crit Care Med 2001; 164: 358-364.

21. Seemungal TA, Donaldson GC, Bhowmik A, Jeffries DJ, Wedzicha JA. Time course and recovery of exacerbations in patients with COPD. Am J Respir Crit Care Med 2000; 161: 1608-1613.

22. Dahl R, Louis APM, Greefhorst DN, et al. Inhaled formoterol dry powder versus ipratropium bromide in chronic obstructive pulmonary disease. Am J Respir Crit Care Med 2001; 164: 778-784.

23. Calverley PMA, Spencer S, Willits LR, Burge PS, Jones PW. Withdrawal from treatment as an outcome in the ISOLDE study of COPD. Chest 2003; 124: 1350-1356.

24. Jones PW, Willits LR, Burge PS, Calverley PMA. The influence of disease severity and the effect of fluticasone propionate on COPD exacerbations in the ISOLDE study. Eur Respir J 2003; 21: 68-73. 